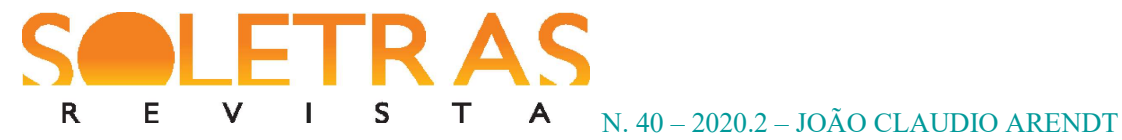

\title{
"Porque espanca as trevas da ignorância": as concepções de biblioteca, leitura e poesia presentes no jornal Despertar (1947-54), de Caxias do Sul ${ }^{1}$
}

\author{
João Claudio Arendt ${ }^{2}$
}

Resumo: No contexto de uma ampla pesquisa sobre periódicos, este artigo analisa as concepções de biblioteca, leitura e poesia presentes no jornal Despertar, publicado em Caxias do Sul entre setembro de 1947 e novembro de 1954. Concebido como forma estratégica de aproximação entre a administração municipal e o público escolar, especialmente o do meio rural, o periódico veiculava notícias sobre educação, orientações pedagógicas para professores, atividades para alunos, poemas para recitar, dicas de higiene e até conselhos sobre agricultura. A fundamentação teórica e crítica da análise advém, entre outros, de estudos realizados por MANGUEL (1997), HARELLOU-LAFARGE e SEGRÉ (2010) e OLIVEIRA e SOUZA (2012).

Palavras-chave: Jornal Despertar. Caxias do Sul. Biblioteca. Leitura. Poesia.

\section{Introdução}

Não molhe o dedo para virar a folha. Não leia depressa. Faça pontuação regular. Procure ouvir seu colega. A boa leitura é sempre um prazer. Procure ler bem. Não perturbe o colega que lê. (DESPERTAR, agosto de 1952, p.2)

Chama a atenção, na história da imprensa de Caxias do Sul (RS), a existência de um periódico fundado em setembro de 1947 e voltado ao público escolar da zona rural do município. Com regularidade mensal, o jornal, intitulado Despertar e subintitulado "Órgão das escolas municipais de Caxias do Sul”, circulou até novembro de 1954. Na capa das sessenta e seis edições, imediatamente abaixo do título, encontram-se as seguintes frases que embasam a

\footnotetext{
${ }^{1} \mathrm{O}$ presente trabalho é resultado parcial do projeto intitulado "Uma história da literatura da Região Metropolitana da Serra Gaúcha (1897-1967) e foi realizado com o apoio da Universidade Federal do Mato Grosso do Sul (UFMS) e da Coordenação de Aperfeiçoamento de Pessoal de Nível Superior - Brasil (CAPES) - Código de Financiamento 001 e Edital Universal.

${ }^{2}$ Pesquisador visitante no PPGLetras da UFMS (Campus Três Lagoas). Doutor em Letras pela PUCRS (Teoria Literária), com Estágio Pós-doutoral pela Universidade Livre de Berlim. Vice-coordenador do GT História da Literatura da ANPOLL. E-mail: joaoarendt@gmail.com. https://orcid.org/0000-0002-2587-2521
} 
sua filosofia: "A educação é a base da sabedoria. O trabalho, base do progresso. A religião e a justiça, bases da ordem."

Idealizada pela professora e então orientadora educacional Ester Justina Troian, a publicação teria sido criada

com a finalidade de servir às escolas e às famílias da zona rural, com a divulgação de boas informações e de propaganda de ensino, despertando entre nossos bravos agricultores, maior interesse pelas escolas às quais confiam a educação dos seus filhos, e entre as crianças um estímulo à sua maior aplicação. (DESPERTAR, ano VI, nº 45, set. de 1952, p. 1)

De forma específica, o mensário objetivava incentivar "o civismo através do culto aos heróis e datas pátrias", estimular "os alunos pelas publicações de trabalhos de aula", ministrar “oportunos ensinamentos de economia e higiene alimentar", promover "um maior entendimento entre o meio rural e a prefeitura municipal", e noticiar "empreendimentos e realizações do poder executivo e legislativo". (DESPERTAR, ano VIII, n 64, set. de 1954, p. 1)

O jornal manteve, do primeiro ao último número, uma certa unidade e regularidade de seções, algumas das quais destacam-se aqui: "Educação e ensino" (com instruções didáticopedagógicas aos professores); "Conselhos sobre agricultura" (também chamada de "Informações rurais"); "Para você criança" (sugestões de textos para leitura e outros produtos culturais); "Colaborações e boa vontade" (espaço reservado a textos criativos, cartas, sugestões e produções dos alunos); "Conselhos úteis (coluna dedicada à higiene e outras utilidades); "Para você recitar" (poemas infantis); "Noticiário" (voltado à divulgação de ações e eventos educacionais do município); "Habilidades" (sugestões de trabalhos manuais, como desenhar, pintar, bordar etc.).

Segundo notícia publicada por ocasião do quarto ano de existência do jornal, entre setembro de 1947 e setembro de 1951, circularam nas escolas em torno de 66.710 exemplares, totalizando 1.820 por mês, com uma média de 8 páginas por volume. No primeiro ano, 15.000 exemplares; no segundo, 16.510; no terceiro, 17.000; e, no quarto ano, 18.200 (DESPERTAR, ano $\mathrm{V}, \mathrm{n}^{\mathrm{o}} 37$, set. de 1951, p. 15). Após essas datas, não se localizaram mais informações sobre 
as tiragens anuais. Observa-se que, no período em questão, há um significativo crescimento do jornal, passando de 15.000 para 18.200, o que parece atestar a ampliação do investimento público no periódico e a sua boa recepção junto à comunidade escolar.

Nesse sentido, merece destaque a nota de agradecimento dos editores "à imprensa desta cidade pelas referências elogiosas que teceram ao modesto órgão do ensino municipal caxiense". (DESPERTAR, ano V, n $\mathrm{n}^{\mathrm{o}}$ 37, set. de 1951, p. 15). Entre outros meios de comunicação que endossaram positivamente o periódico, encontra-se o Correio Rio-grandense, jornal da ordem dos capuchinhos que nas décadas de 1940-50, com o propósito de "combater leituras más, indecentes e irreligiosas" produzidas pela "grande propriedade estatal, tão do gosto dos socialistas”, fez uma ampla campanha pela boa imprensa, com a publicação de listas de obras, autores, editoras e revistas que podiam ou não ser lidos pelos seus fiéis. É assim que, em 12 de junho de 1950, por exemplo, o Correio enumera títulos de revistas infantis condenáveis e recomendáveis. Entre as primeiras, aparecem O Lobinho, Os Três Valentes, O Guri Shasam, Herói, Seleções Coloridas, O Globo Juvenil, Biriba, Cômico, Ai, Mocinho, Superman e Edição Maravilhosa. Já entre as de leitura recomendada, figuram Bandeirantes, Vida juvenil, Jornalzinho, Estrela, Vida infantil, Era uma vez, Tiquinho e o jornal Despertar. ${ }^{3}$

Isso posto, o presente artigo, debruçando-se de modo especial sobre a coluna "Educação e ensino", objetiva discutir as concepções de biblioteca, leitura e poesia que orientaram e fundamentaram as ações pedagógicas das "abnegadas mestras" (DESPERTAR, ano VIII, n64, set. de 1954, p.1) da educação pública de Caxias do Sul, entre 1948 e 1954.

\section{"A biblioteca escolar e sua função"}

Em novembro de 1948, com o mesmo título que abre esta seção, os editores de Despertar publicam um texto chamando a atenção para a importância das bibliotecas escolares na atividade docente e, de modo especial, na formação dos alunos. Além de "elemento de informação e de auxílio ao estudo - aperfeiçoar o treino da leitura - despertar e manter o gosto pela leitura e pela boa linguagem" (DESPERTAR, ano II, nº11, nov. de 1948, p. 2),

\footnotetext{
${ }^{3}$ Mais detalhes sobre esse tema podem ser obtidos no seguinte artigo: ARENDT, João Claudio; MENEGOTTO, Roberto Rossi; LIMA, Letícia. Leitura e censura na Serra Gaúcha: considerações sobre o jornal Correio Riograndense (1940-1950), Revista Labirinto, Porto Velho, ano XVII, vol. 27, n 1, Jul-Dez de 2017, p. 193-209.
} 
consideradas finalidades principais, as bibliotecas das escolas atuariam positivamente sobre os seguintes aspectos da vida estudantil:

a) O sentido da ordem, do asseio, da economia, obtido pelo trato cuidadoso dos livros, arrumação, etc.

b) O espírito de cooperação, desenvolvido pela própria constituição da biblioteca e seu funcionamento, pelo modo por que os trabalhos ali são realizados, etc.;

c) $\mathrm{O}$ respeito à liberdade e ao trabalho dos outros, o hábito de leitura, pela necessidade do silêncio e da ordem na biblioteca;

d) O hábito de leitura. (DESPERTAR, ano II, nº11, nov. de 1948, p. 2)

Observa-se que o foco recai sobre detalhes de natureza comportamental, como asseio, ordem, economia, cooperação, silêncio e respeito aos colegas, e não necessariamente sobre as vantagens intelectuais da leitura de livros na biblioteca.

A leitura silenciosa - "olhos perscrutando a página, língua quieta" -, segundo Manguel (1999, p.59), tornou-se usual no Ocidente apenas no século X. Antes disso, o ambiente das bibliotecas era marcado pelo barulho das tabuletas sendo espalhadas, pelo ruído dos pergaminhos sendo abertos e pelos leitores "murmurando para si mesmos uma infinidade de histórias diferentes" (MANGUEL, 1999, p. 60). É provável, consoante o autor, que os antigos não se importassem com o alarido e nem soubessem ser possível ler de outro modo - até porque, historicamente, "o texto escrito era uma conversação, posta no papel para que o parceiro ausente pudesse pronunciar as palavras destinadas a ele” (MANGUEL, 1999, p. 61).

Já as noções de asseio, ordem e economia parecem convergir para as maneiras de ler na biblioteca, explicitadas por Harellou-Lafarge e Segré. Apenas no século XX, com a popularização da leitura e a disponibilidade dos impressos a todos os tipos de público, a relação com os livros e as formas de apropriação se modificaram substancialmente. Os livros ficaram à mercê de leitores que "anotam no livro, comentam por escrito certas passagens do texto, rasgam as páginas para uso próprio, dobram a obra, quebram-lhe as pontas" (HARELLOULAFARGE \& SEGRÉ, 2019, p. 135).

Nesse sentido, a perspectiva adotada pelos editores do jornal Despertar a respeito da biblioteca ampara-se na ideia de que ela, por sua aura sagrada, assemelha-se ao comportamento 
adotado pelo devoto em um templo religioso: silêncio para meditação e conexão com o transcendente; asseio para não conspurcar a pureza dos objetos sagrados; ordem para harmonizar com a ritualística; e economia para conservar o patrimônio.

Ao final do texto em análise, reforça-se que, "no convívio de livros sadios, inspiradores, instrutivos e educativos, a nossa juventude formará o hábito da leitura, tomará o gosto pelo estudo, e elevará a cultura do nosso povo para maior progresso da nossa pátria" (DESPERTAR, ano II, nº11, nov. de 1948, p. 2). Pode-se inferir que, se o hábito não faz o monge, o hábito da leitura pode fazer o leitor - daí o destaque do texto para o fato de que "cada escola deve ter sua biblioteca que forneça aos alunos livros para serem lidos gratuitamente".

\section{"Importância da leitura"}

Simultaneamente ao incentivo para o uso da biblioteca escolar, o jornal se voltava à promoção da leitura e se engajava na campanha contra o analfabetismo. De acordo com Oliveira e Souza, no final da década de 1940, o Brasil tinha uma população de quase 52 milhões de habitantes, com um índice de 50\% de analfabetos entre as pessoas maiores de 15 anos:

Naquele período, 360 municípios brasileiros não contavam com qualquer prédio escolar, e os existentes nos demais municípios apresentavam instalações extremamente precárias, principalmente os da zona rural. Lembremos que, em $1950,63,84 \%$ da população viviam no campo. (OLIVEIRA; SOUZA, 2012, p. 1904).

Convém lembrar que, finda a Era Vargas (1930-1945), que deixou um saldo negativo para o avanço dos direitos civis, foi lançada, em 1947, mesmo ano da criação do jornal Despertar, a Campanha de Educação de Adolescentes e Adultos (CEAA), que propunha erradicar o analfabetismo do país. Dois anos depois, era lançada a Campanha Nacional de Educação Rural (CNER), voltada à população do campo, que, praticamente isolada, não tinha acesso à educação formal, nem aos bens culturais necessários ao progresso humano e material. 


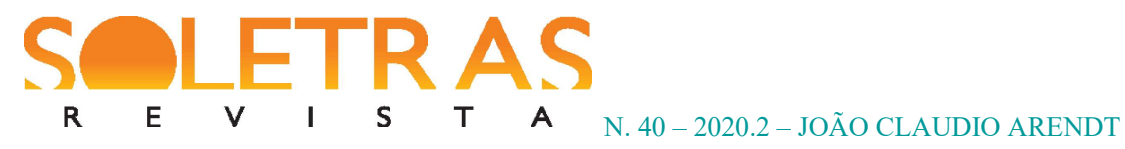

Os dados referentes à educação brasileira da década de 1940, mesmo que trazidos aqui de forma muito sintética, são pertinentes pelo fato de lançarem um pouco de luz tanto sobre o direcionamento do jornal Despertar ao universo familiar e escolar rural de Caxias do Sul (vide a já mencionada seção "Conselhos sobre agricultura"), quanto sobre a sua investida em prol da leitura, da biblioteca e da literatura. Na "Campanha contra o analfabetismo", o jornal parece perfilar-se às campanhas da época, nas quais “o analfabeto [...] era caracterizado como incapaz [...] de participar da sociedade de modo pleno. [...] delineava-se a imagem da 'criança grande', que não conseguia desempenhar suas responsabilidades pessoais, sociais e profissionais de forma competente" (OLIVEIRA; SOUZA, 2012, p. 1910).

Veja-se, nessa perspectiva, o que o jornal registra:

Quem não sabe ler vive como uma pessoa que tenha sempre os olhos tapados. É como o cego que há de ser guiado por onde os outros o queiram levar. Ou, então, andará tropeçando.

$[\ldots]$

O homem analfabeto não é de todo livre: é escravo de sua ignorância. (DESPERTAR, ano I, nº 06, maio de 1948, p. 2)

A comparação do analfabeto com o cego e o escravo deixa entrever, por um lado, a sua condição de dependência e de servidão e, por outro, de alheamento para com "os tesouros da sabedoria de todos os homens e ainda as grandes verdades do Evangelho" (DESPERTAR, ano I, no 06, maio de1948, p. 2). De modo indireto, também se delineia aí a imagem da "criança grande" mencionada por Oliveira e Souza, já que o analfabeto não seria de todo livre e estaria sempre na condição de sujeição à própria ignorância.

A campanha feita pelo jornal ainda sugere que quem é alfabetizado deve ensinar o analfabeto a ler, para que diante dos seus olhos se abra a porta de "um novo mundo": "Você que já sabe ler, ensine a uma pessoa de sua família, a um vizinho, a um amigo. [...] Ajude também a abrir essa porta aos outros!” (DESPERTAR, ano I, nº 06, maio de 1948, p. 2). Essa noção de solidariedade converge para o que, à época, emanava da Constituição de 1946, a partir da qual a educação nacional deveria proporcionar as condições necessárias para a escola implantar e consolidar princípios de liberdade e solidariedade humanas (SANTOS; PRESTES; VALE, 2006). 


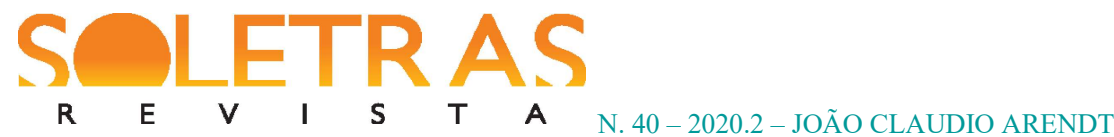

No mesmo contexto da "importância da leitura", o periódico trouxe à luz outras publicações focadas no tema, sugerindo, inclusive, atividades para a sua aprendizagem e aprimoramento. Sob o argumento de que "a criança deseja aprender a ler" (mas, se essa vontade não se manifestar naturalmente no primeiro ano, ela deve ser despertada pelos mestres), são apresentados os objetivos de leitura, divididos em antigos e modernos. Naqueles, destacavamse:

$\left.1^{\circ}\right)$ domínio das dificuldades mecânicas da leitura;

$2^{\circ}$ ) desenvolvimento do hábito de ler em voz alta;

$3^{\circ}$ ) um estímulo do interesse pela boa leitura. (DESPERTAR, ano V, $n^{\circ} 39$, mar. de 1952, p. 2).

Já entre os objetivos modernos, "muito mais ricos", o jornal propõe:

$1^{\circ}$ ) preparar a criança a utilizar a leitura para um ajustamento, como um recurso na vida que a espera; $2^{\circ}$ ) leitura para informação: anúncios, avisos, fontes de informação, leitura de jornais, a leitura como recurso para a vida em comunidade; $3^{\circ}$ ) adaptar-se às situações da vida; auxiliar os outros; responder a perguntas que lhe são formuladas; $4^{\circ}$ ) recreativa: para entreter-se e para entreter os outros; para aumentar a cultura; para utilizar as (sic) horas de lazer. (DESPERTAR, ano V, nº 39, mar. de 1952, p. 2).

Comparadas as finalidades, infere-se que a leitura, antes focada em habilidades genéricas e essencialmente mecânicas, progride para propósitos mais específicos de formação e uso. $\mathrm{O}$ domínio das dificuldades mecânicas e o hábito de ler em voz alta perdem o valor em si mesmos, e o estímulo pela "boa leitura" (certamente de textos clássicos e formativos) é substituído por gêneros textuais da vida cotidiana e moderna, como anúncios, avisos e jornais informativos, os quais ajustariam a criança ao mundo futuro. Igualmente, sobressai a leitura de natureza recreativa, de entretenimento, de lazer.

Entre as décadas de 1950 e 1970, de acordo com Oliveira (2015, p. 32), 
cada vez mais se desenvolviam métodos alternativos de ensino: surgiram as escolas experimentais e a ideia de um ensino centrado no aluno e nas suas necessidades difundia-se por todo o país. A rede pública de ensino se expandia de modo muito rápido: cada vez mais, as camadas populares ingressavam na escola. Embora muitas escolas continuassem a adotar antigos comportamentos e métodos, tornando desagradáveis e temidos os momentos em que as práticas de leitura se davam, um número significativo passou a adotar as novas posturas. Nesse período, aumentaram também os meios de acesso à leitura: bibliotecas populares, inclusive ambulantes, foram criadas em muitas cidades do país e o número de livrarias também aumentou significativamente.

No entanto, reconhecedores de que esses objetivos não se alcançam sem esforço e orientação, o jornal propõe o desenvolvimento das seguintes habilidades ("hábitos"):

Reconhecimento de palavras, associação de sons a impressões várias, formação de grupos de palavras, reconhecimento de pausas, enumeração rápida de palavras, frases e períodos com sequência, fluentemente. A estes atos mecânicos reúnem-se os de interpretação da leitura. Hábitos para utilização da leitura como recurso de informações: usar o índice, dicionário, catálogos etc. (DESPERTAR, ano V, nº 39, mar. de 1952, p. 2).

Parece que um dos aspectos mais importantes e inovadores dessa enumeração repousa sobre o da "interpretação da leitura". Mesmo que não se explicite o sentido da "interpretação", que pode ser tomada na mesma perspectiva de "compreensão", ela por si mesma já constitui uma tentativa de superar a velha decoreba e a repetição mecânica de passagens do texto.

Um exemplo que pode ilustrar o tipo de abordagem textual comum nos anos 1940-50 é encontrado no livro Páginas literárias $(1943)^{4}$, de autoria de Francisco da Silveira Bueno, "lente catedrático de filologia portuguesa na Universidade de São Paulo". Em consonância com o decreto número 4.244, de 9 de abril de 1942, assinado pelo então ministro Gustavo Capanema, Bueno afirma, na nota "aos srs. Professores", ter dado "especial cuidado à formação do VOCABULÁRIO, base essencial do aprendizado das línguas vivas" e acrescentado comentários gramaticais, tirados do próprio assunto", ou seja, de cada texto de leitura.

\footnotetext{
${ }^{4}$ Em 1949, o livro alcançou a quarta edição, fato que atesta o seu sucesso editorial. 


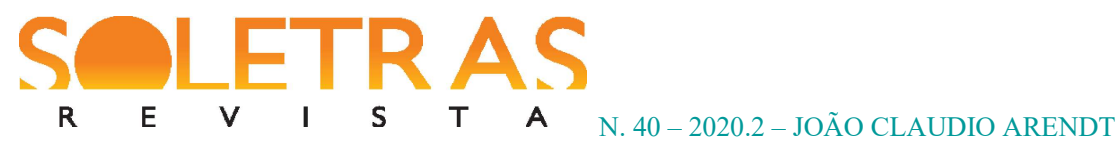

Assim, divididos em três assuntos - família, escola e pátria -, os textos são explorados sempre na mesma perspectiva: vocabulário, comentários gramaticais, exercícios e biografia do autor. Veja-se, por exemplo, a proposta de trabalho da obra com o poema "No lar", de Casimiro de Abreu:

Longe da pátria, sob um céu diverso Onde o sol como aqui tanto não arde, Chorei saudades do meu lar querido

- Ave sem ninho que suspira à tarde.

No mar - de noite - solitário e triste Fitando os lumes que no céu tremiam, Ávido e louco nos meus sonhos d'alma Folguei nos campos que meus olhos viam.

Era pátria e família e vida e tudo, Glória, amores, mocidade e crença, E, todo em choros, vim beijar as praias Por que chorara nessa longa ausência.

Eis-me na pátria, no país das flores, - O filho pródigo a seus lares volve, E consertando as suas vestes rotas, O seu passado com prazer revolve!

Eis meu lar, minha casa, meus amores, A terra onde nasci, meu teto amigo, A gruta, a sombra, a solidão, o rio Onde o amor me nasceu - cresceu comigo.

Os mesmos campos que eu deixei criança, Árvores novas... tanta flor no prado!... Oh! como és linda, minha terra d'alma, - Noiva enfeitada para o seu noivado!

Foi aqui, foi ali, além... mais longe, Que eu sentei-me a chorar no fim do dia; - Lá vejo o atalho que vai dar na várzea... Lá o barranco por onde eu subia!...

Acho agora mais seca a cachoeira Onde banhei-me no infantil cansaço... - Como está velho o laranjal tamanho Onde eu caçava o sanhaçu a laço!...

Como eu me lembro dos meus dias puros! 


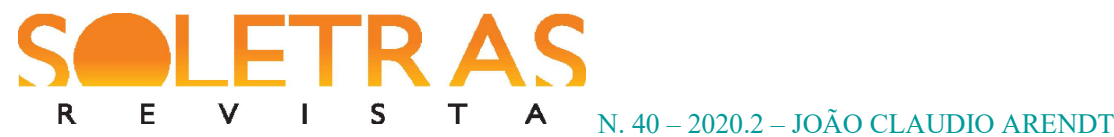

Nada m'esquece... e esquecer quem há de?

- Cada pedra que eu palpo, ou tronco, ou folha,

Fala-me ainda dessa doce idade!

Eu me remoço recordando a infância,

E tanto a vida me palpita agora

Que eu dera oh! Deus! a mocidade inteira

Por um só dia de viver d'outrora!

É a casa!... as salas, estes móveis... tudo,

O crucifixo pendurado ao muro...

O quarto do oratório... a sala grande

Onde eu temia penetrar no escuro!...

E ali... naquele canto... o berço armado!

E minha mana, tão gentil, dormindo!

E mamãe a contar-me histórias lindas

Quando eu chorava e a beijava rindo!

Oh! primavera! oh! minha mãe querida!

Oh! mana! - anjinho que eu amei com ânsia -

Vinde ver-me, em soluços - de joelhos -

Beijando em choros este pó da infância! (BUENO, 1944, p. 12- 13)

Vinculado a dois dos três temas mencionados no livro, o poema é seguido pelas seções "vocabulário" e "exercícios", na qual não há foco na interpretação do texto. A atividade somente utiliza o tema do poema para propor atividades orais e escritas:

1) Faça uma reprodução em prosa desta poesia. - Diga, oralmente, o que sentia o poeta longe do lar.

2) Faça uma imitação, contando o que sente quando está no colégio ou na escola, ausente do seu lar.

3) Descreva o seu lar. - Como é a sua casa? - Em que bairro está situada? Como é a rua em que se encontra? - Existe alguma curiosidade lá? - Como são os vizinhos?

4) Narre o caminho que faz da sua casa ao colégio. (BUENO, 1944, p. 13)

Como se pode notar, não há questões conduzam a uma leitura mais aprofundada do texto, reduzindo-se os exercícios a atividades de criação com base, estritamente, na vivência pessoal 


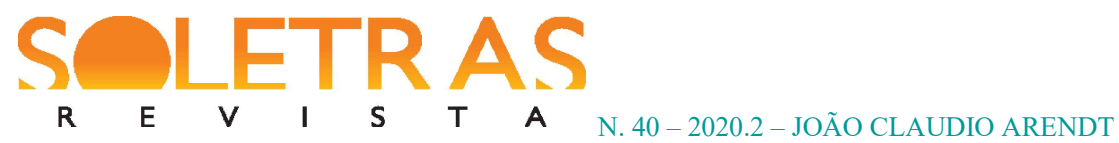

do aluno. Nessa perspectiva, a abordagem textual presente nas páginas seguintes mantém a mesma estratégia, sem alterações.

Parece, portanto, promissor o fato de, em um contexto como esse, que emerge do material preparado e publicado por Silveira Bueno, o jornal Despertar propor a "interpretação" de textos na formação de leitores. Em matéria anterior, sobre leitura silenciosa e oral, datada de 1948, essa habilidade já aparecia vinculada ao ato de ler em voz alta. Veja-se:

Não nos basta, porém, efetuar leitura silenciosa eficiente. Devemos ter capacidade de ler bem, oralmente. Às vezes não se interpreta com clareza e não se aprecia devidamente certos trechos de leitura, senão lendo-os em voz alta. (DESPERTAR, ano I, n ${ }^{\circ}$ 7, jun. de 1948, p. 2 - grifo nosso).

Do ponto de vista do tema aqui em análise, é pertinente, ainda, destacar uma proposta pedagógica assinada pela professora Norma C. Sant'Ana (DESPERTAR, ano V, nº 37, set. de 1951, p. 2), em que se associa a aprendizagem da leitura ao jogo. Tomado como meio e não como fim, o jogo coletivo contribuiria para aumentar o interesse dos alunos pelos trabalhos escolares, a cooperação com colegas, os hábitos de governo, o domínio de situações diversas e o treino social. Como sugestões para a fixação de vocabulário, são elencadas as seguintes atividades lúdicas: jogo das faltas, jogo do desenho, jogo do chapéu, jogo de sílabas e jogo do dado de cartolina. Observe-se a proposta: 

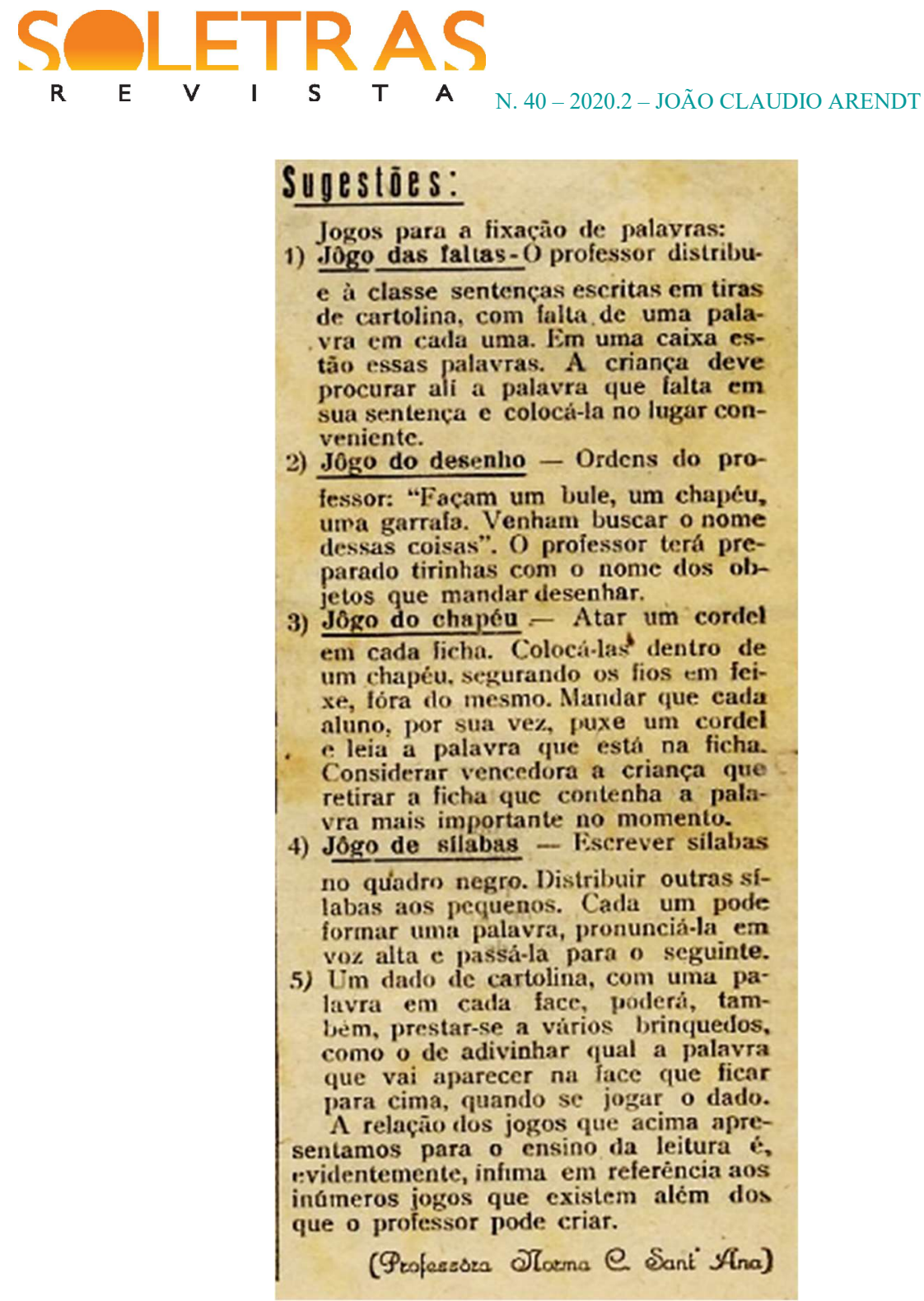

Fig.1 (DESPERTAR, ano V, no 37, set. de 1951, p. 2)

Como se vê, embora a dinâmica dos jogos propostos seja imensamente simples, ela aponta para uma mudança sensível na atitude pedagógica da escola da época, a qual, como bem se sabe, era marcada pela exigência do silêncio e da passividade - condições agravadas em momento político posterior, em função da censura instituída a alunos e docentes.

\section{"Para você recitar": o ensino da poesia}


Entendida como "um meio educativo que exerce grande influência sobre a imaginação da criança” (DESPERTAR, Ano II, nº10, 10/1948), a poesia encontrou um espaço significativo no jornal Despertar, seja como objeto de reflexão por parte dos editores, seja como texto indicado para fruição em voz alta.

Na seção "Para você recitar", por exemplo, eram publicados poemas infantis - a maioria sem indicação de autoria - para recitação. ${ }^{5}$ Pautadas em temas pátrios, familiares e escolares, as produções poéticas assumiam uma função pedagógica, procurando incutir valores nos leitores mirins. No mês de novembro de 1953, vieram a público três poemas para recitação: "A bandeira", "Hino nacional" e "Ao Brasil". Em todos eles, o tom de exaltação à bandeira e à pátria são explícitos, como se pode ver na composição a seguir:

\author{
À Bandeira \\ Salve! altivo Pendão da minha terra \\ Que balança nos ares docemente, \\ E sempre, a triunfar na paz e na guerra, \\ Da nossa alma, és a imagem resplendente. \\ Em tua alma de luz vibra e palpita \\ Num turbilhão de amor e de harmonia, \\ A coragem de Osório, imensa, invita, \\ E a glória excelsa de Marcílio Dias. \\ Irmãos! ajoelhemos como em sonho, \\ Da Pátria ante esse altar imaculado, \\ Desce do azul um frêmito risonho, \\ E o Cruzeiro do Sul brilha estrelado. \\ Assim! que o novo amor que jamais cansa, \\ Num fervor infinito e alvissareiro, \\ Canta um hino vibrante de esperança, \\ A glória do Estandarte brasileiro.
}

(DESPERTAR, Ano VII, n57, 11/1953)

\footnotetext{
${ }^{5}$ É interessante observar que grande parte dos poemas desta seção eram copiados, sem nenhuma indicação da fonte, da revista Sesinho, também fundada em 1947 pelo escritor Vicente Guimarães, o Vovô Felício. Igualmente, foram observadas ressonâncias com publicações da revista $O$ malho, criada no Rio de Janeiro, em 1902.
} 


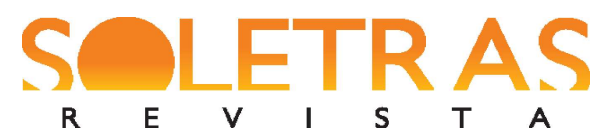

N. $40-2020.2$ - JOÃO CLAUDIO ARENDT

Publicado na edição de novembro, o poema situa-se no cenário de comemoração da proclamação da República e dialoga com outros textos sobre essa data cívica. Estampado na capa da edição, por exemplo, figura um resumo histórico dos motivos que teriam levado à proclamação da República e, na página 2, um texto sobre a bandeira nacional, cujo dia é comemorado em 19 de novembro. Convém destacar que, durante todo o período de circulação do mensário, as principais datas cívicas e religiosas eram lembradas e comemoradas, tais como: a Páscoa e o Natal; o dia das mães, dos pais e da criança; e o dia independência, da república e da bandeira.

Ainda na senda do trabalho com a poesia, em um artigo sob o título "Linguagem e o ensino da poesia", o jornal Despertar propugnava que "o ensino da poesia encerra muitos valores educativos e, por isso mesmo, deve ser praticado na escola primária. A poesia deve ser aproveitada não só como parte de programas festivos, mas também como atividade escolar comum.” (DESPERTAR, ano V, n 42, mar. de 1952, p. 2). A função pedagógica da poesia fica, portanto, bem clara nessa passagem como ferramenta para "oportunizar o aprimoramento do vocabulário, o gosto pela linguagem elegante e o desejo de falar e escrever bem". (DESPERTAR, ano V, no 42, mar. de 1952, p. 2).

Todavia, segundo o jornal, a escolha dos textos poéticos para o trabalho pedagógico não pode ser feita de forma aleatória, mas, sim, com base em três princípios: arte, moral e acessibilidade. A arte consistiria "não só na beleza da forma como na intensidade da emoção que desperta no ritmo que encerra". Na perspectiva moral, são condenadas "as poesias que encerram aspectos impróprios à idade das crianças a que se destinam e que treinam emoções prematuras". No mesmo critério de exclusão, entrariam as composições que, falhas de arte, teriam como propósito único uma pregação moral. E, finalmente, do ponto de vista da acessibilidade, os poemas devem "ser simples na forma e no conteúdo, curtas e de sentido e linguagem fáceis." (DESPERTAR, ano V, nº 42, jun. de 1952, p. 2). Todavia, a partir do terceiro ano, aconselha-se a escolha de poesias com maior grau de "dificuldade de interpretação".

Esses três princípios parecem ter sido extraídos da obra $A$ poesia no curso primário: Imetodologia; II coletânea seriada, de Alaíde Lisboa de Oliveira, Zilah Frota e Marieta Leite, publicada em 1939, pela Livraria Francisco Alves. Na seção dedicada à metodologia, são estabelecidos critérios de seleção de poemas para leitura escolar, nos quais se destacam justamente os três critérios adotados pelo jornal Despertar. Para as autoras, resultante de um 


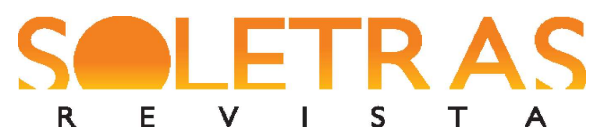

misto de subjetividade e experiência pessoal, o sentido artístico encontrar-se-ia "na beleza da forma, na emoção, no sentimento, na música, no ritmo, no colorido, na harmonia, na imaginação, na vida”. (OLIVEIRA; FROTA; LEITE, 1939, p.27). Apesar disso, a beleza de um poema não residiria unicamente nas rimas, nas palavras, no ritmo e nas ideias, mas, sim, "na própria essência da poesia". Por isso, reconhecer "o harmonioso, o belo, o sublime" em uma composição poética, só seria possível a partir da convivência intensa com a atmosfera artística. Veja-se:

Uma professora será capaz de julgar da presença ou ausência, de sentido artístico, em uma poesia, se se familiarizar com a literatura. A muita leitura literária, especialmente poética, dará percepção mais segura, poder mais real de selecionar, olhos para ver o joio e para ver o trigo. Leia a professora os grandes poetas, nossos e estrangeiros; leia-os muito; leia-os sempre. (OLIVEIRA; FROTA; LEITE, 1939, p. 27)

Claro está que a seleção textual pelo critério artístico não se embasa em valores absolutos do ponto de vista técnico, mas em elementos de natureza pessoal, subjetiva, alcançados pela experiência da leitura.

Já o critério moral - para cuja explanação as autoras dizem abrir mão de "considerandos filosóficos" - é claro e positivo em se tratando de poesia para crianças. Na perspectiva da obra em questão, "a alma infantil é de uma delicadeza extrema e o educador tem obrigação de evitarlhe choques, descargas, emoções que podem trazer consequências graves para a vida". (OLIVEIRA; FROTA; LEITE, 1939, p. 29). Isso, porque a criança é concebida como “inacabada - de corpo, de coração e de espírito".

Daí, as autoras condenarem a leitura, por crianças, de poemas com temas impróprios, que apresentem conceitos errôneos ou motivos inconvenientes à idade e ao desenvolvimento: "Poupemos a almas em botão exaltações poéticas de sentimentos indesejáveis: revolta, despeito, paixão, etc.” (OLIVEIRA; FROTA; LEITE, 1939, p. 29). O mesmo critério valeria para as composições de temática amorosa, cuja fruição poderia ser feita em um momento oportuno, que não no da infância. Igualmente, elas condenam os textos poéticos carregados de moralismo, mas despidos de arte, já que “o objetivo da literatura não é pregar moral, 
categoricamente, mas apelar para as emoções, para o coração e para a alma do homem." (OLIVEIRA; FROTA; LEITE, 1939, p. 30)

Finalmente, o critério da acessibilidade deveria calcar-se na simplicidade da linguagem, da forma, do assunto/motivo/pensamento ou do sentimento. Para as autoras, "a poesia é acessível quando parte dos interesses, dos conhecimentos, das experiências da criança." (OLIVEIRA; FROTA; LEITE, 1939, p. 30). Em outros termos, porque "a ideia poética só pode ser apreendida posteriormente à ideia da realidade", o texto deve partir do mundo da criança e sugerir-lhe novos interesses e experiências. Em hipótese alguma, o poema poderia ser uma promessa de acomodação futura na compreensão da criança. Por isso, o foco recai no presente, na assimilação imediata.

Como se vê, tudo indica que os critérios propostos pelo jornal Despertar para a escolha de poemas foram extraídos do livro A poesia no curso primário. Inclusive a apresentação dos textos em sala de aula encontra ressonâncias na seguinte metodologia proposta pelas autoras:

1 - Introdução, pela qual deverá ligar o assunto sobre o qual versa a poesia às experiências anteriores dos educandos.

2 - Leitura da poesia pelo professor: essa leitura deverá ser feita de forma muito expressiva, podendo ser precedida, nas classes mais adiantadas, de um breve comentário sobre a vida e a obra do seu autor.

3 - Estudo apreciativo da poesia: por esse estudo os alunos penetram no sentido da poesia.

[...]

4 - Após uma segunda leitura pelo professor deve ser feita a leitura ou recitação pelos alunos, exigindo-se deles, nessa ocasião, dicção perfeita, expressão adequada, sem exagero nem afetação. (DESPERTAR, ano V, $\mathrm{n}^{\circ} 42$, jun. de 1952, p. 2). ${ }^{6}$

Para além do destaque à criação e utilização de bibliotecas para leitura, estudo e pesquisa, à leitura como habilidade a ser desenvolvida e à fruição de textos poéticos, o jornal engajou-se tanto em temáticas referentes à aprendizagem da linguagem, quanto na divulgação de eventos relacionados à educação do município, tais como: inauguração de escolas, cursos de aprimoramento para professores, concursos de perguntas e respostas, de redação e de ilustração,

\footnotetext{
${ }^{6}$ Essa mesma orientação, com pequenas diferenças, já havia sido anunciada na edição de outubro de 1948.
} 
exposição de trabalhos de alunos, bibliotecas circulantes dos professores etc. - um conjunto de materiais que pode ser explorado com a devida atenção em outro momento.

\section{Considerações finais}

Pode-se afirmar, em primeiro lugar, que a concepção de biblioteca do jornal Despertar estava em sintonia com o pensamento em voga nos anos 1940-50, como um espaço em que se aprendia a praticar a leitura silenciosa e se exercitava a sociabilidade. Além disso, a biblioteca contribuiria para incutir nos estudantes as noções de ordem, limpeza e economia, em razão do contato com a organização dos livros nas estantes e com a impecável arrumação e limpeza do espaço. Entretanto, se a proposta de incentivo à visita dos alunos do meio rural às bibliotecas escolares naquela época aparece interessante e muito promissora aos olhos de hoje, ainda não existem dados tabulados sobre a quantidade e a qualidade das bibliotecas no interior do munícipio de Caxias do Sul que possam confirmar a prática. A dúvida sobre esse aspecto aumenta mais, quando, passados setenta anos, o Censo MEC 2017 indica que 61\% das escolas públicas brasileiras não têm biblioteca ou sala de leitura, sendo que $68 \%$ desse total de estabelecimentos pertencem às redes municipais.

Em segundo lugar, percebe-se em relação à leitura que, apesar de ela ainda ser estimulada pelos colaboradores do periódico como hábito e habilidade mecânica, já havia certa preocupação em ensinar o aluno a interpretar aquilo que lia, evitando a mera repetição e a tradicional memorização de textos. Isso permite inferir que a visão de leitura assumida à época toma ares modernos, avançando para além do simples ato de decodificar palavras e frases, e reproduzi-las nas respostas de questionários. Entretanto, somente o acesso e a análise de planos de aula remanescentes daquela época poderiam confirmar se, de fato, as escolas da zona rural de Caxias do Sul estavam avançadas no quesito da leitura e interpretação de textos.

Finalmente, a noção de poesia, no periódico analisado, assume uma indiscutível função pedagógica na formação escolar, seja para desenvolver habilidades orais, seja para incutir valores morais. Ao que parece, o aspecto positivo da visão sobre a escolha e a leitura de poemas na escola reside tanto na valorização da imaginação infantil, quanto no critério artístico. Mesmo que a questão da imaginação seja colocada de forma favorável nas publicações do periódico, 


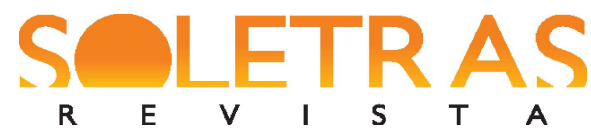

N. $40-2020.2-$ JOÃO CLAUDIO ARENDT

ela não poderia ser estimulada sem se considerar a adequação do tema e da linguagem à idade do aluno, evitando-se, assim, danos “às almas em botão”. Já o aspecto artístico não deixa de ser pertinente quando a escolha é feita a partir de uma perspectiva pessoal e subjetiva de um leitor experiente, tal como se propõe no periódico, e não com base em critérios teóricos. Considerando-se a inexistência de cursos superiores para a formação de docentes em Caxias do Sul e região nas décadas de 1940-50, é de se presumir que quem fosse um bom leitor, também seria um bom mediador de leitura.

\section{Referências}

A BIBLIOTECA ESCOLAR E SUA FUNÇÃO. Despertar, Caxias do Sul, ano II, $\mathrm{n}^{\circ} 11$, nov. de 1948, p. 2.

A LEITURA EFICIENTE E SUA IMPORTÂNCIA FUNDAMENTAL PARA VIDA. Despertar, Caxias do Sul, ano I, n⿳0 7, jun. de 1948, p. 2.

ALGUNS CONSELHOS PARA AS CRIANÇAS. Despertar, Caxias do Sul, ano VI, nº 44, ago. de 1952, p. 2.

ANIVERSÁRIO DE FUNDAÇÃO DO MENSÁRIO DESPERTAR. Despertar, Caxias do Sul, ano $\mathrm{V}, \mathrm{n}^{\mathrm{o}} 37$, set. de 1951, p.15.

ARENDT, João Claudio; MENEGOTTO, Roberto Rossi; LIMA, Letícia. Leitura e censura na Serra Gaúcha: considerações sobre o jornal Correio Riograndense (1940-1950), Revista Labirinto, Porto Velho, ano XVII, vol. 27, nº 1, Jul-Dez de 2017, p. 193-209.

CAMPANHA CONTRA O ANALFABETISMO. Despertar, Caxias do Sul, ano I, nº 6, maio. de 1948 , p. 2.

HORELlOU-LAFARGE, Chantal; SEGRÉ, Monique. Sociologia da leitura. São Paulo: Ateliê Editorial, 2010.

IMPORTÂNCIA DA LEITURA. Despertar, Caxias do Sul, ano V, no 42, mar. de 1952, p. 2.

LINGUAGEM E O ENSINO DA POESIA. Despertar, Caxias do Sul, ano VI, nº 45, jun. de 1952, p. 2.

MANGUEL, Alberto. Uma história da leitura. São Paulo: Companhia das Letras, 1999.

O PRIMEIRO LUSTRO. Despertar, Caxias do Sul, ano VI, nº 45, set. de 1952, p. 1.

OLIVEIRA, Alaíde Lisboa de; FROTA, Zilah; LEITE, Marieta. A poesia no curso primário: I - Metodologia; II - Coletânea seriada. Rio de janeiro: Livraria Francisco Alves, 1939.

OLIVEIRA, Rosemary Lapa de. Leitura no Ensino Médio e orientações governamentais. 


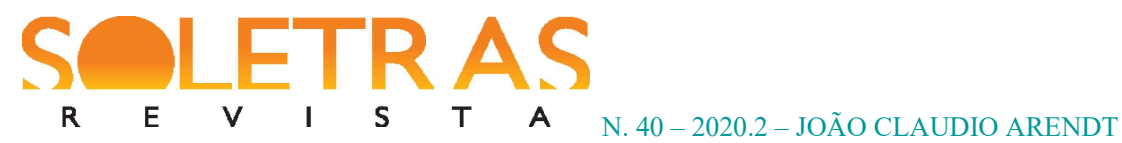

Revista Leitura, Maceió, v. 2, nº 56, jul-dez de 2015.

OLIVEIRA, Letícia Borges de; SOUZA, Sauloéber Tarsio de. História das campanhas de alfabetização de adultos: iniciativas para os moradores do campo. In: IX Seminário Nacional de Estudos e Pesquisas "História, Sociedade e Educação no Brasil", Universidade Federal da Paraíba, João Pessoa, Anais Eletrônicos, 08.2012, p. 1903-1918.

ORIENTAÇÕES PARA POESIAS E DECLAMAÇÕES. Despertar, Caxias do Sul, ano II, no 10, out. de 1948, p. 2.

RETRATOS DA LEITURA EM BIBLIOTECAS ESCOLARES, Instituto Pró-livro, Rio de Janeiro, 2018.

REVISTAS QUE ALIMENTAM E REVISTAS QUE ENVENENAM. Correio Rio-grandense, Garibaldi/Caxias do Sul, ano 41, nº 28, 12 de jul. de 1950, p. 1.

SANT'ANA, Norma C. Da aprendizagem da leitura. Despertar, Caxias do Sul, ano V, $\mathrm{n}^{\mathrm{o}} 37$, set. de 1951, p. 2.

SANTOS, Irene da Silva Fonseca dos; PRESTES, Reulcinéia Isabel; VALE, Antônio Marques do. Brasil, 1930- 961: Escola Nova, LDB e disputa entre escola pública e escola privada. Revista HISTEDBR, Campinas, n. 22, jun. 2006, p. 131-149.

\title{
"Because it beats the darkness of ignorance": the conception of library, reading and poetry present in the journal Despertar (1947-54), from Caxias do Sul
}

\begin{abstract}
In the context of an extensive research on journals, this paper analyzes the conception of library, reading and poetry present in the journal Despertar, published in Caxias do Sul between September 1947 and November 1954. Designed as a strategic way of bringing municipal administration and schools closer, especially the rural ones, the journal carried news about education, pedagogical guidance for teachers, activities for students, poems to recite, hygiene tips and advices on agriculture. The theoretical and critical foundation of the analysis comes, among others, from studies by MANGUEL (1997), HARELLOU-LAFARGE and SEGRÉ (2010) and OLIVEIRA and SOUZA (2012).
\end{abstract}

Keywords: Journal Despertar. Caxias do Sul. Library. Reading. Poetry.

Recebido em: 16 de março de 2020.

Aceito em: 22 de junho de 2020. 